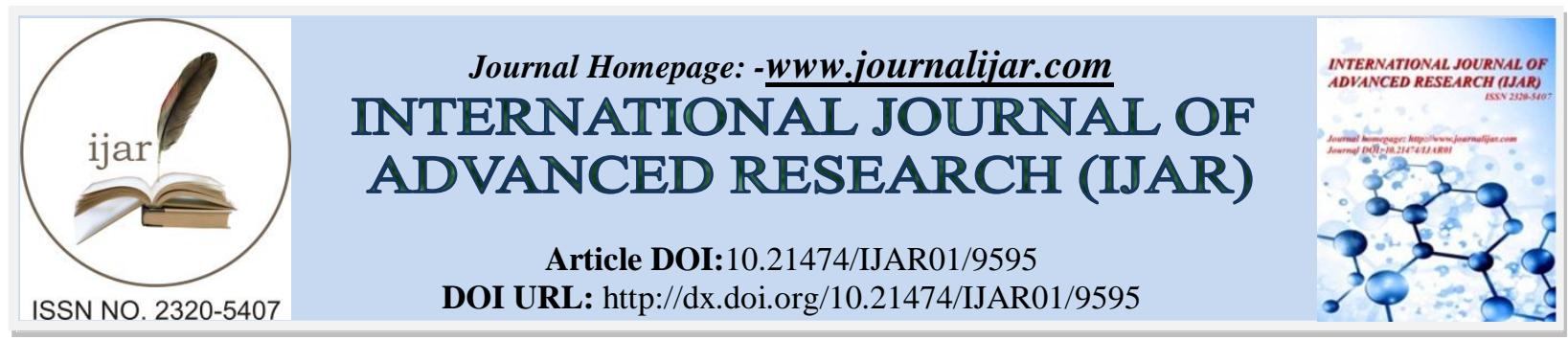

RESEARCH ARTICLE

\title{
ASSESSMENT OF QUALITY OF LIFE AMONG PARENTS OF CHILDREN WITH THALASSEMIA.
}

\section{Padma Bakthavatchalam ${ }^{1}$ and Dr. Vetriselvi.P ${ }^{2}$.}

1. B sc. IV year student, college of Nursing, JIPMER, Puducherry.

2. Assistant professor, college of Nursing, JIPMER, Puducherry.

\section{Manuscript Info}

Manuscript History

Received: 18 June 2019

Final Accepted: 20 July 2019

Published: August 2019

Keywords

Assessment, Quality of life ,

\section{Abstract}

Background :Thalassemia is an serious public health issue in India. Thalassemia is an autosomal recessive disorder characterized by partial or no production of alpha or beta globin chains which form part of the structure of the hemoglobin in the red blood cells. The life expectancy and survival of the patient have been increased due to the introduction of treatments include frequent blood transfusions and iron chelating therapies. However the child may ended up with some complications. Parents of these children have many problems in various aspects of physical, psychological, social, economical and communications.

Aim : The study was undertaken to assess the quality of life among parents of children with thalassemia.

Methods : A cross-sectional study was conducted among 43 parents of thalassemic children Using convenient techniques the samples were selected. Data was collected using standardized tool (PedsQL ${ }^{\mathrm{TM}}$ ) through personal interview. The data was analyzed using descriptive and inferential statistics.

Results :The study revealed that overall mean and standard deviation score of quality of life of parents of children

with thalassemia is $67.76 \pm 17.28$. Majority of the parents of children with thalassemia had neither poor nor good quality of life $25(58.1 \%)$, $14(32.6 \%)$ had poor quality of life and less parents of children with thalassemia had good quality of life $4(9.3 \%)$. Number of children had shown statistically significant association between level of quality of life among parents of children with thalassemiawith chi-square value of $\left(\chi^{2}=13.9\right.$, d. $\left.\mathrm{f}=6\right)$ at $\mathrm{p}<0.05$ level.

Conclusion :The worries of the parents about their child's future affects the family in leading a normal life. So it is important to improve the physical, emotional and social wellbeing of parents by providing proper counselling and relaxation therapies.

Copy Right, IJAR, 2019,. All rights reserved.

\section{Introduction:-}

Worldwide, thalassemia is an increasingly serious public health problem due to the high prevalence. In developing countries such as India, leading cause of death in thalassemic patient is non-compliance with the treatment due to psychological and psychosocial factors and economical factors. Thalassemia is an autosomal 
recessive disorder characterized by partial or no production of alpha or beta globin chains which form part of the structure of the hemoglobin in the red blood cells. ${ }^{(6)}$ It was the group of hereditary hemolytic anemia characterized by reduction in the synthesis of hemoglobin. It produces hypochromic microcytic anemia due to defective hemoglobinization of RBCs, hemolysis and ineffective erythropoiesis. ${ }^{(7)}$ The life expectancy and survival of these patients have been increased dramatically over previous decades through the introduction of regular blood transfusion therapy and iron chelating therapies. ${ }^{(5)}$

Parents of thalassemic children have many concerns regarding their appearance of the child, bone deformities, short stature, poor self-image, frequent hospital visits for blood transfusion, delayed or absent sexual development and impaired fertility and other associated complications. ${ }^{(1)}$ They feel depressed, worried, frustrated, despaired, hopeless and helpless and also have numerous physical, emotional, psychosocial and financial sufferings. ${ }^{(2)} \mathrm{A}$ significant psychological impact, causing emotional burden, hopelessness, and difficulty with social integration and parents experience negative thoughts about their life, guilt, increased anxiety and low self-esteem. Parents impact on child's physical ,emotional, and mental wellbeing and affecting numerous areas of a child's life, including health development, academic progress and quality of life. ${ }^{(8)}$ Taking into account the above factors, it is essential to maintain and improve parent's health for betterment of the family and development of the child.

Hence this study aims to assess and determine the quality of life among the parents of children suffering from thalassemia. It is necessary that health care workers should provide support and education by appropriate planning, it helps the nurses in making appropriate interventions. Training life skills to the parents of thalassemic children can be very helpful in reducing the problems and difficulties imposed on these parents and helpful to determine the parent's burden of care to improve their family and social function.

\section{Objectives:-}

Primary Objective:

To assess the quality of life among parents of children with thalassemia.

\section{Secondary Objectives :}

To identify the socio-demographic variable associated with the quality of life among parents of children with thalassemia.

\section{Methodology:-}

A cross-sectional study was conducted among 43 parents of children with thalassemia who fulfilled the inclusion and exclusion criteria, attending the pediatric casualty, OPD and pediatric ward and receiving treatment for more than 6 months. Convenient sampling technique was used to select the study sample.

The Data collection tool consists of two sections. The first section was on socio-demographic profile, the second section was Pediatric Quality of Life Inventory (PedsQL) Family Impact Module Scale Questionnaire which consists of 36 items used to assess the quality of life among parents of children with thalassemia. It is a standardized questionnaire developed by JW Varni(1998) PedsQL Family Impact module have 6 subscales measuring the parents self-reported functioning: Physical functioning(6items), Emotional functioning(5items), Social domain(4items), Cognitive functioning(5items), worry(5items), Communication domain(3items); as well as 2 subscales measuring the parent-reported family functioning: Daily activities(3items), Relationship of the family domains(5items). The total score is 144, the PedsQL total score is calculated by sum of the 36 item scores divided by the number of items answered. The content validity for questionnaire was obtained from two nursing experts. The data was collection period was 3 months. Data was collected through personal interview, for each participant 30 minute was spent to provide their response. The results were analyzed using descriptive and inferential statistics. The quality of life was expressed as mean and standard deviation, the association of level of quality of life with socio-demographic variables were carried out using ANOVA. All statistical analysis were performed at 5\% level of significance .

\section{Result:-}

Out of the 43 parents of children who were interviewed, the majority of the parents of children $33(76.7 \%)$ of study population were in the age group between 25-35years. Most of the them 30 (69.8\%) belongs to female in gender. Most of the parents $32(74.4 \%)$ came from nuclear family with $25(58.1 \%)$ belonging to more than rs.2000 in income. Majority of them were residing in rural area $38(88.4 \%)$ and completed primary school $19(44.2 \%)$. 
Majority of the parents of children were working on private / agriculture in occupation $28(64.1 \%)$ and most of them are having two children $20(46.5 \%)$.

Figure 1 and 2 and 3 depicts the Percentage wise distribution of age, gender and number of children among parents of children with thalassemia.

Figure 4 and 5 depicts the percentage,Mean and standard deviation of level of quality of life (domain-wise) among parents of children with thalassemia

Table 1 Reveals that,Frequency and Percentage wise Distribution of demographic variables among parents of children with thalassemia.

Table 2 shows that Frequency and percentage wise distribution of the level of quality of life among parents of children with thalassemia. Majority of the parents of children with thalassemia had neither poor nor good quality of life $25(58.1 \%), 14(32.6 \%)$ had poor quality of life and less parents of children with thalassemia had good quality of life $4(9.3 \%)$. The level of quality of life among parents of children with thalassemia mean and standard deviation is $(67.76 \pm 17.28)$.

Table 3 shows that Mean and standard deviation of level of quality of life (domain-wise) among parents of children with thalassemia. The mean and standard deviation ofthe level of quality of life (domain-wise) among parents of children with thalassemia, Physical functioning, Emotional functioning, social functioning, Cognitive functioning, Communication, Worry, Daily activities andFamily Relationships is $(8.186 \pm 5.201),(9.720 \pm 4.505),(8.209 \pm 4.126)$, $(6.348+4.363),(7.767 \pm 2.552),(14.16 \pm 2.776),(5.465+2.771)$, and $(7.907 \pm 3.950)$.

Table 4 depicts that the demographic variables Number of children had shown statistically significant association with association between level of quality of life among parents of children with thalassemiawith chi-square value of $\left(\chi^{2}=13.9\right.$, d.f $\left.=6\right)$ at $\mathbf{p}<\mathbf{0 . 0 5}$ level. The other demographic variables had not shown statistically significant association withlevel of quality of life among parents of children.

\section{Discussion:-}

The existence of a life-threatening disease like thalassemia in children causes physical and psychological stress in parents and that can predispose them to psychological disorders. The life expectancy and prognosis of thalassemic children were improved due the availability of modern treatments, the life-long measures creates an impact on the parents life and those measures are expensive and needs proper adherence for the significant results. Thus it is important to determine the quality of life of parents of children with thalassemia keeping in mind the study was conducted among 43 parents of children with thalassemia who were came for treatment and blood transfusion in pediatric casualty. The investigator obtained an informed consent from the parents data was collected using the standardized Pediatric Quality of Life Inventory (PedsQL) ${ }^{\mathrm{Tm}}$ family impact module scale. The responses were analyzed through descriptive and inferential statistics and the discussion about the findings were arranged according to the objectives of the study.

The primary objective of the study was to assess the quality of life among parents of children with thalassemia, the study revealed that majority of the parents of children with thalassemia had neither poor nor good quality of life 25 $(58.1 \%), 14(32.6 \%)$ had poor quality of life and less parents of children with thalassemia had good quality of life 4 $(9.3 \%)$.

Similar study was conducted by sharma S et al, A comparative study to assess the quality of life in children with thalassemia and their care givers in India. It was found that a significantly higher proportion of care givers of cases (parents of thalassemic children) reported poor health compared with caregivers of controls(parents of healthy children), $\{29.2 \%$ vs. $2.5 \%, \mathrm{p}<0.001\}$

The secondary objective of the study was to identify the socio-demographic variable associated with the quality of life among parents of children with thalassemia. The study found that the demographic variables Number of children had shown statistically significant association with association between level of quality of life among parents of children with thalassemiawith chi-square value of $\left(\chi^{2}=13.9, \mathrm{~d} . \mathrm{f}=6\right)$ at $\mathbf{p}<\mathbf{0 . 0 5}$ level. The other 
demographic variables had not shown statistically significant association withlevel of quality of life among parents of children.

In contradicted to the present study, the study conducted by s kaheniet.al revealed that there was no significant correlation between quality of life and demographic variables. Correlation between social relationship and education was significant ( $\mathrm{p}$ value $<0.0001$ ).

\section{Summary:-}

The aim of the study was to assess the quality of life among parents of children with thalassemia and to identify the socio-demographic variables associated with their quality of life. A cross-sectional study was conducted among 43 parents of thalassemic children in JIPMER Pediatric casualty using non-probability convenient sampling technique. The data collected through a personal interview using Pediatric Quality of Life Inventory (PedQL ${ }^{(T M)}$ ) Family Impact Module Scale. All statistical analysis were done by using descriptive and inferential statistics.

The major findings of the study were;

1. Among 43 parents, The level of quality of life among parents of children with

thalassemia mean and standard deviation is $(67.76 \pm 17.28)$.

2. The mean and standard deviation of the level of quality of life (domain-wise) among parents of children with thalassemia, Physical functioning, Emotional functioning, social functioning, Cognitive functioning, Communication, Worry, Daily activities andFamily Relationships is $(8.186 \pm 5.201),(9.720 \pm 4.505),(8.209 \pm 4$. $(6.348 \pm 4.363),(7.767 \pm 2.552),(14.16 \pm 2.776),(5.465 \pm 2.771)$, and $(7.907 \pm 3.950)$.

3. There was a significant association between the number of children of parents of children with thalassemia and the quality of life (P value $<0.05)$

4. The other demographic variables had not shown statistically significant association withlevel of quality of life among parents of children.

\section{Conclusion:-}

The study showed that the overall mean and standard deviation scores of quality of life of parents of children with thalassemia was $67.76 \pm 17.28$. There is no other significant association between the socio-demographic variables and the quality of life of parents except the number of children. The parents who had poor quality of life 14(32.6) were suggested to counseling and relaxation therapies. The conditions of the thalassemic children when compared with the healthy children of same parents increase the parental feeling of love towards to those sick children in the family which creates the feeling of discrimination among the children, this feeling of love is turned into jealousy among the other children. Moreover more level of care and attention given to the thalassemic child. The study concludes that worries of the parents about the child's future were found to face difficulties in leading a normal family life and creating a positive atmosphere at home. So, effective coping is an important source to create the well-being and psychological adjustments in stressful situations and affects on physical and psychological health of parents.

Table 1:-Frequency and Percentage wise Distribution of demographic variables among parents of children with thalassemia.

\begin{tabular}{|c|c|c|c|}
\hline \multicolumn{4}{|c|}{$(\mathrm{N}=43)$} \\
\hline $\begin{array}{l}\text { Sl. } \\
\text { NO }\end{array}$ & $\begin{array}{l}\text { DEMOGRAPHIC } \\
\text { VARIABLES }\end{array}$ & $\begin{array}{l}\text { FREQUENCY } \\
(\mathbf{N})\end{array}$ & $\begin{array}{c}\text { PERCENTAGE } \\
(\%)\end{array}$ \\
\hline \multirow[t]{4}{*}{1} & \multicolumn{3}{|l|}{ Age in years } \\
\hline & Less than 25 years & 4 & 9.3 \\
\hline & $25-35$ years & 33 & 76.7 \\
\hline & More than 35 years & 6 & 14 \\
\hline \multirow[t]{3}{*}{2} & \multicolumn{3}{|l|}{ Gender } \\
\hline & Male & 13 & 30.2 \\
\hline & Female & 30 & 69.8 \\
\hline \multirow[t]{3}{*}{3} & \multicolumn{3}{|l|}{ Type of family } \\
\hline & Nuclear & 32 & 74.4 \\
\hline & Joint & 11 & 25.6 \\
\hline \multirow[t]{3}{*}{4} & \multicolumn{3}{|l|}{ Income in rupees } \\
\hline & Less than rs. 2500 & 18 & 41.9 \\
\hline & More than rs. 2500 & 25 & 58.1 \\
\hline
\end{tabular}




\begin{tabular}{|c|c|c|c|}
\hline 5 & \multicolumn{3}{|l|}{ Domicile } \\
\hline & Urban & 5 & 11.6 \\
\hline & Rural & 38 & 88.4 \\
\hline \multirow[t]{6}{*}{6} & \multicolumn{3}{|l|}{ Educational qualification } \\
\hline & Illiterate & 9 & 20.9 \\
\hline & Primary school & 19 & 44.2 \\
\hline & High school & 11 & 25.6 \\
\hline & Higher secondary & 3 & 7 \\
\hline & Graduate & 1 & 2.3 \\
\hline \multirow[t]{5}{*}{7} & \multicolumn{3}{|l|}{ Occupation } \\
\hline & Un-employee & 0 & 0 \\
\hline & House wife & 15 & 34.9 \\
\hline & Private/agriculture & 28 & 64.1 \\
\hline & Government & 0 & 0 \\
\hline \multirow[t]{5}{*}{8} & \multicolumn{3}{|l|}{ Number of children } \\
\hline & One & 4 & 9.3 \\
\hline & Two & 20 & 46.5 \\
\hline & Three & 18 & 41.9 \\
\hline & More than 3 & 1 & 2.3 \\
\hline
\end{tabular}

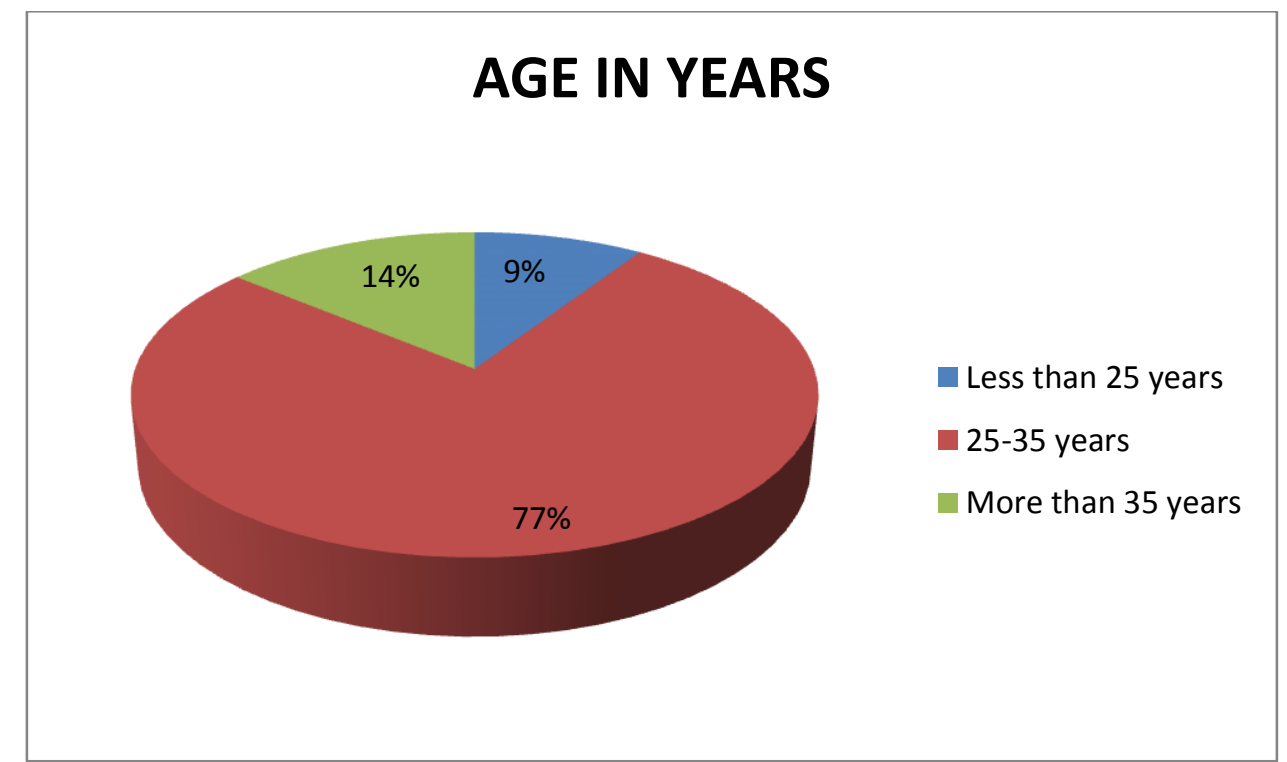

Fig 1:-Percentage wise distribution of age in years among parents of children with thalassemia 


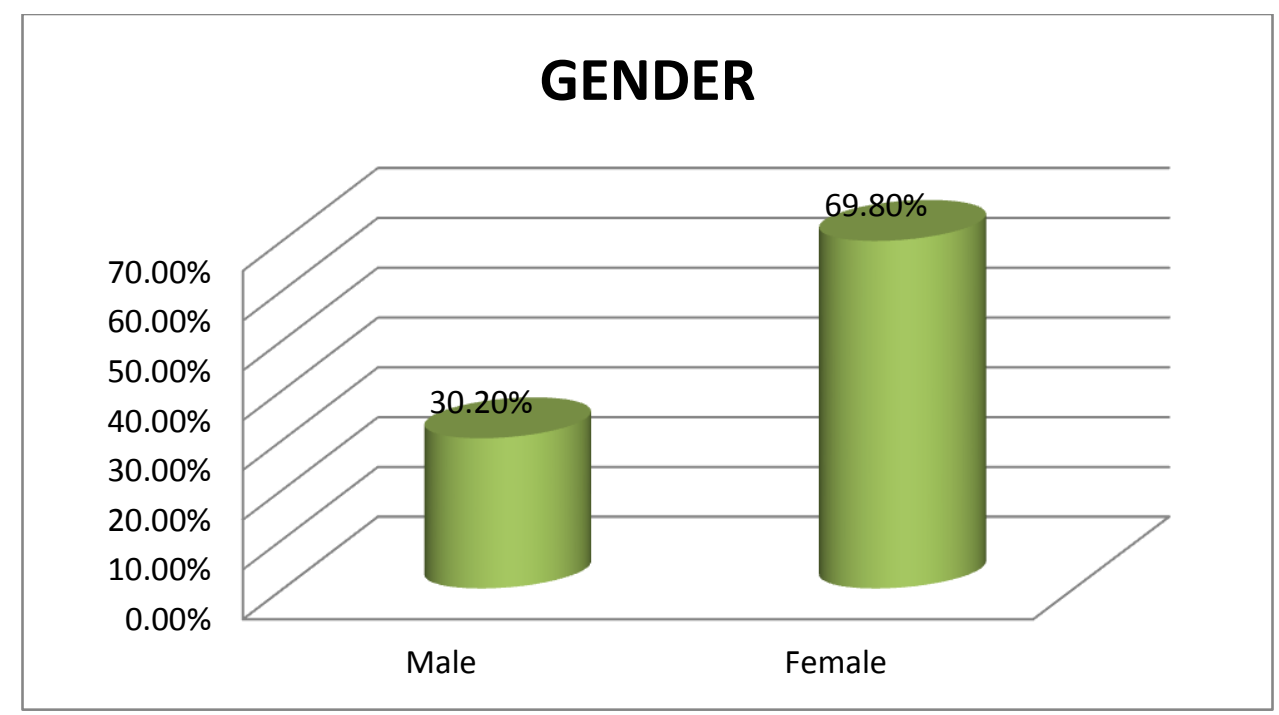

Fig 2:-Percentage wise distribution of gender among parents of children with thalassemia

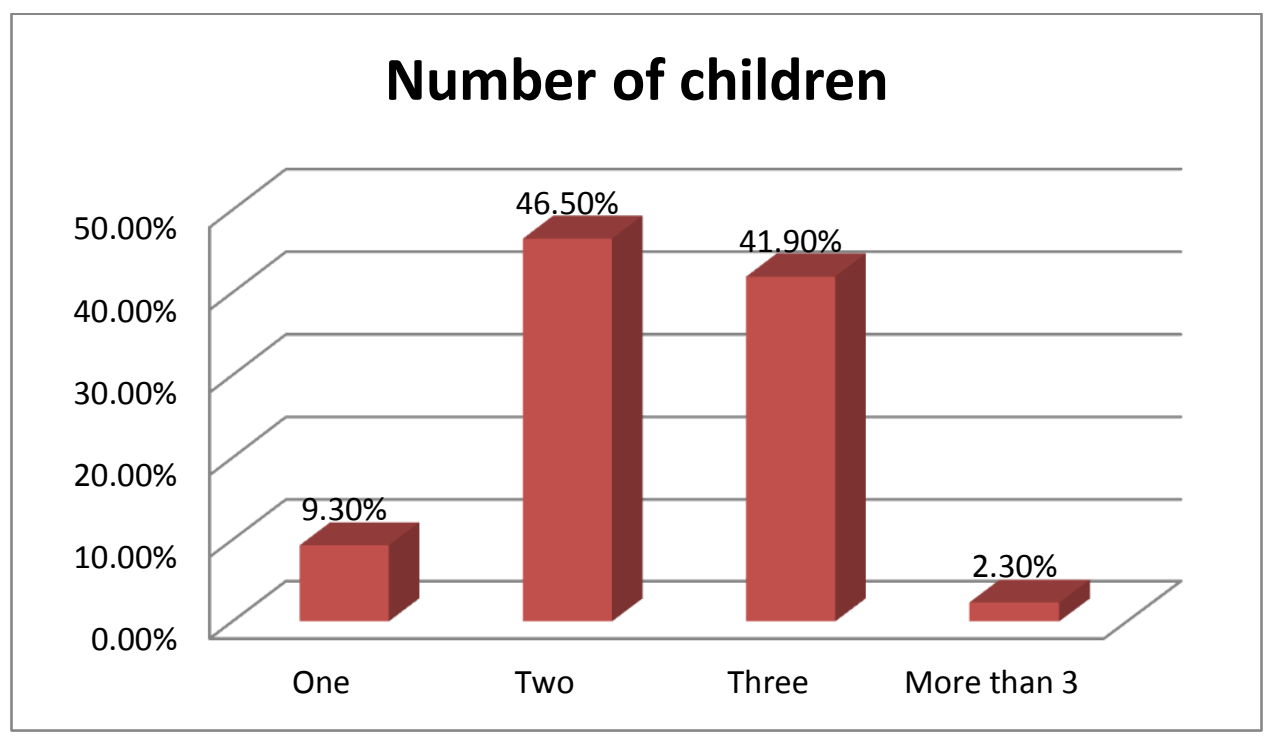

Fig 3:-Percentage wise distribution of Number of children among parents of children with thalassemia

Table 2:-Frequency and percentage wise distribution of level of quality of life among parents of children with thalassemia.

\begin{tabular}{|c|c|c|c|c|}
\hline $\begin{array}{l}\text { LEVEL OF QUALITY OF LIFE AMONG } \\
\text { PARENTS OF CHILDREN WITH } \\
\text { THALASSEMIA. }\end{array}$ & $\mathbf{N}$ & $\%$ & MEAN & S.D \\
\hline Very poor & 0 & 0 & \multirow[b]{5}{*}{67.76} & \multirow[b]{5}{*}{17.28} \\
\hline Poor & 14 & 32.6 & & \\
\hline $\begin{array}{l}\text { Neither poor } \\
\text { nor good }\end{array}$ & 25 & 58.1 & & \\
\hline Good & 4 & 9.3 & & \\
\hline Very good & 0 & 0 & & \\
\hline
\end{tabular}




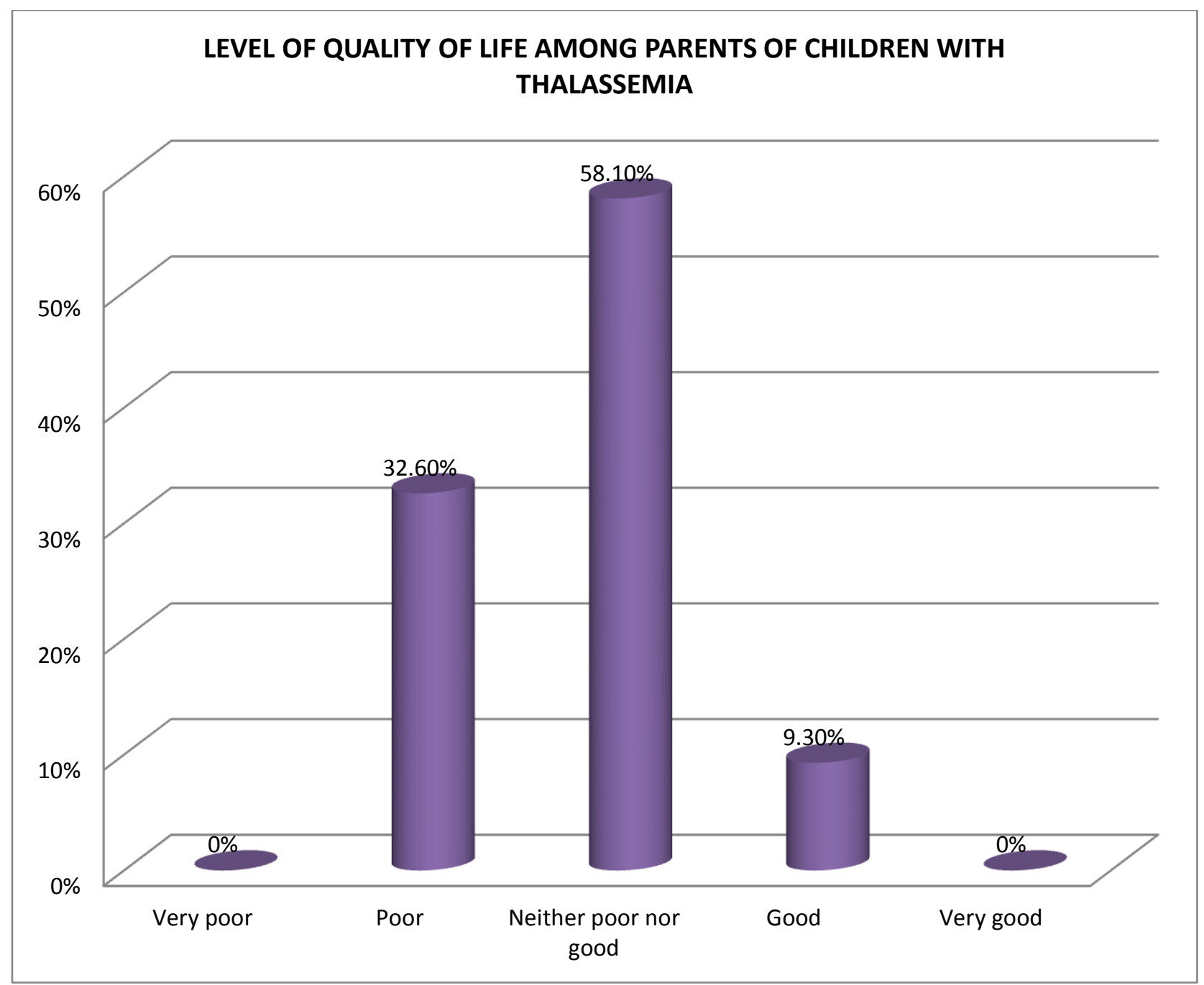

Fig 4:-Percentage wise distribution of level of quality of life among parents of children with thalassemia. 


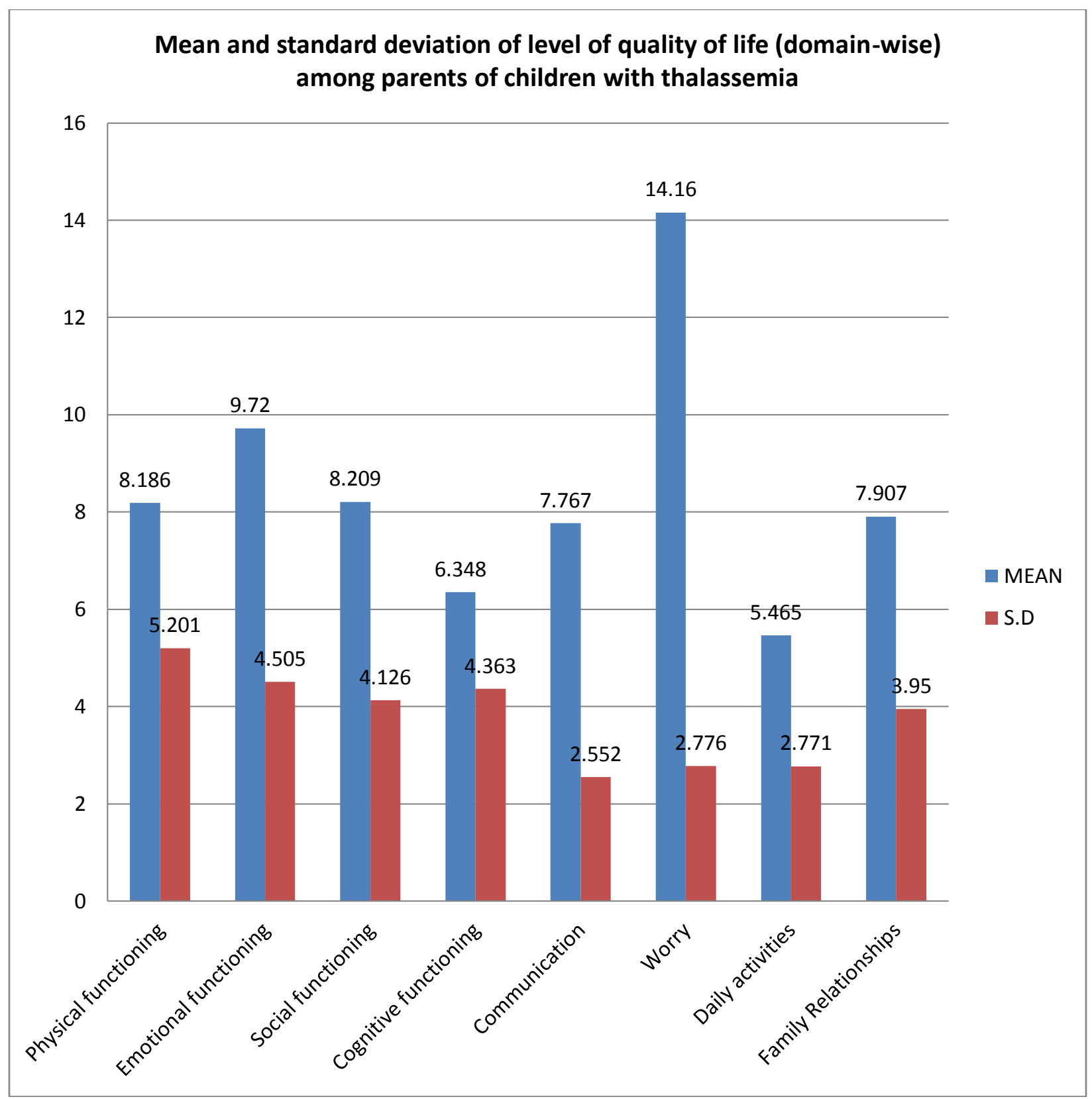

Fig 5:-Mean and standard deviation of level of quality of life (domain-wise) among parents of children with thalassemia

Table 3:-Mean and standard deviation of level of quality of life (domain-wise) among parents of children with thalassemia

\section{LEVEL OF QUALITY OF LIFE AMONG PARENTS OF CHILDREN WITH THALASSEMIA. (domain-wise)}

\begin{tabular}{|l|c|c|}
\hline \multicolumn{1}{|c|}{$\begin{array}{c}\text { LEVEL OF QUALITY OF LIFE AMONG PARENTS OF } \\
\text { CHILDREN WITH THALASSEMIA. (domain-wise) }\end{array}$} & \\
& & \\
& & \\
\hline Physical functioning & MEAN & S.D \\
\hline Emotional functioning & 8.186 & 5.201 \\
\hline Social functioning & 9.720 & 4.505 \\
\hline
\end{tabular}




\begin{tabular}{|l|c|c|}
\hline Cognitive functioning & 6.348 & 4.363 \\
\hline Communication & 7.767 & 2.552 \\
\hline Worry & 14.16 & 2.776 \\
\hline Daily activities & 5.465 & 2.771 \\
\hline Family Relationships & 7.907 & 3.950 \\
\hline
\end{tabular}

Table 4:-Association of level of quality of life among parents of children with thalassemia with their selected demographic variables.

\begin{tabular}{|c|c|c|c|c|c|c|c|c|c|c|}
\hline & & & & & & & & 43) & & \\
\hline SL. & DEMOGRAPHIC & & & ALI'] & OF LI & & & $\mathbf{X}^{2}$ & df & p-value \\
\hline NO & VARIABLES & & & $\begin{array}{r}\mathrm{NE} \\
\mathrm{P} \\
\mathrm{NOI}\end{array}$ & $\begin{array}{l}\text { [ER } \\
\text { R } \\
\text { DOD }\end{array}$ & & OD & & & \\
\hline & & $\mathbf{N}$ & $\%$ & $\mathbf{N}$ & $\%$ & $\mathbf{N}$ & $\%$ & & & \\
\hline 1 & Age in years & & & & & & & & & \\
\hline & Less than 25 years & 0 & 0 & 4 & 100 & 0 & 0 & 3.521 & 4 & 0.475 \\
\hline & $25-35$ years & 12 & 36.4 & 18 & 54.5 & 3 & 9.1 & & & \\
\hline & More than 35 years & 2 & 33.3 & 3 & 50 & 1 & 16.7 & & & \\
\hline 2 & Gender & & & & & & & 2.820 & 2 & 0.240 \\
\hline & Male & 6 & 46.2 & 7 & 53.8 & 0 & 0 & & & \\
\hline & Female & 8 & 26.7 & 18 & 60 & 4 & 13.3 & & & \\
\hline 3 & Type of family & & & & & & & .099 & 2 & 0.952 \\
\hline & Nuclear & 10 & 31.2 & 19 & 59.4 & 3 & 9.4 & & & \\
\hline & Joint & 4 & 36.4 & 6 & 54.5 & 1 & 9.1 & & & \\
\hline 4 & Income in rupees & & & & & & & .150 & 2 & 0.928 \\
\hline & Less than rs. 2500 & 6 & 33.3 & 10 & 55.6 & 2 & 11.1 & & & \\
\hline & More than rs. 2500 & 8 & 32 & 15 & 60 & 2 & 8 & & & \\
\hline 5 & Domicile & & & & & & & 3.42 & 2 & 0.181 \\
\hline & Urban & 3 & 60 & 1 & 20 & 1 & 20 & & & \\
\hline & Rural & 11 & 28.9 & 24 & 63.2 & 3 & 7.9 & & & \\
\hline 6 & Educational qualification & & & & & & & 4.902 & 8 & 0.768 \\
\hline & Illiterate & 2 & 22.2 & 5 & 55.6 & 2 & 22.2 & & & \\
\hline & Primary school & 7 & 36.8 & 11 & 57.9 & $\frac{2}{1}$ & 5.3 & & & \\
\hline & High school & 3 & 27.3 & 7 & 63.6 & 1 & 9.1 & & & \\
\hline & Higher secondary & 1 & 33.3 & 2 & 66.7 & 0 & 0 & & & \\
\hline & Graduate & 1 & 100 & 0 & 0 & 0 & 0 & & & \\
\hline 7 & Occupation & & & & & & & .190 & 2 & .0909 \\
\hline & Un-employee & 0 & 0 & 0 & 0 & 0 & 0 & & & \\
\hline & House wife & 5 & 33.3 & 9 & 60 & 1 & 6.7 & & & \\
\hline & Private/agriculture & 9 & 32.1 & 16 & 57.1 & 3 & 10.7 & & & \\
\hline & Government & 0 & 0 & 0 & 0 & 0 & 0 & & & \\
\hline 8 & Number of children & & & & & & & 13.9 & 6 & 0.031* \\
\hline & One & 3 & 75 & 1 & 25 & 0 & 0 & & & \\
\hline & Two & 6 & 30 & 13 & 65 & 1 & 5 & & & \\
\hline & Three & 5 & 27.8 & 11 & 61.1 & 2 & 11.1 & & & \\
\hline & More than 3 & 0 & 0 & 0 & 0 & 1 & 100 & & & \\
\hline
\end{tabular}

p $<0.05$ significant*

\section{References:-}

1. Ali S, Sabih, Jehan, et.al. Psychological distress and coping strategies among parents of beta-thalassemia major parents. ICCGE. 2012; 27(2): 124-28.

2. Ammand SA, Mubeen SM, et.al. Parents opinion of quality of life (QOL) in Pakistani thalassemicchildren . J

Pak Med Assoc . 2011; 61(5): 470-3. 
3. Anum J, Dasti R. Caregivers burden, spirituality, and psychological well-being of parents having children with thalassemia. J Relig Health. 2016; 55(3) : 941-55.

4. Aziz K, Sadaf B et.al. Psychosocial problems of Pakistani parents of thalassemic children: a cross sectional study. Biopsychosoc Med.2012;6:15.

5. Brittenham GM, Griffith PM, et al. Efficacy of deferoxamine in preventing complications of iron overload in patients with thalassemia major. New Engl J Med.1994; 331(9): 567-73.

6. Clegg JB, Weatherall DJ. Thalassemia and malaria: new insights into an old problem. Proc Assoc Am physicians. 1999;111(4):278-82.

7. Datta P. Textbook of paediatric nursing. $3^{\text {rd }}$ ed. New Delhi: Jaypee; 2014.

8. Deepak SS, Jay SP, et.al. Assessment of psychosocial impact on parents of thalassemic children. SAS J Med. 2017; 4(3): 57-60.

9. Kaur R. Psychosocial and financial burden on parents of children with thalassemia. IJCR.2018; 10(12):7626872.

10. Olivieri NF, Brittenham GM. Iron-chelating therapy and the treatment of thalassemia. Blood. 1997; 89(3): 73961.

11. Pouraboli B, Abedi AH, et.al .The burden of care: Experiences of parents of children with thalassemia. J Nurs Care. 2017; 6:389.

12. Scarpelli AC, Paivas.M, et al. The Pediatric Quality of Life Inventory ${ }^{\mathrm{TM}}$ (PedQL) family impact module: reliability and validity of the Brazilian version. Health Qual life Out. 2008; 35 (6):7525-26.

13. Shahraki-vahed A, Firouzkouhi M, Abdollahimohammad A, Ghalgaie J. Lived experiences of Iranian parents of beta-thalassemia children. J Multidiscip healthc.2017;10:243-51.

14. Shaligram D, Girimaji SC, Chaturvedi SK. Quality of life issues in caregivers of youngsters with thalassemia. Indian J Pediatr. 2007; 74 (3) : 275-78.

15. Telfer P, Coen PG, Christou S, Hadjigavriel M, Kolnakou A, Pavlides N, et al. Survival of medically treated thalassemia patients in Cyprus. Trends and risk factors over the period 1980-2004. Haematologica.2006; 91(9): 1187-92.

16. Yamashita R, Sobota A, Trachtenberg F, Xu Y, Pakbaz Z et al. The impact of the child with thalassemia on the family : Parental Assessment by child Health Questionnaire. Blood.2009;114(22):1371. 